\title{
Integrated monte carlo-evolutionary programming technique for distributed generation studies in distribution system
}

\author{
Nur Ainna Shakinah Abas ${ }^{1}$, Ismail Musirin ${ }^{2}$, Shahrizal Jelani ${ }^{3}$, Mohd Helmi Mansor ${ }^{4}$, Naeem M. S. \\ Honnoon $^{5}$, Muhammad Murtadha Othman ${ }^{6}$ \\ ${ }^{1,2}$ Faculty of Electrical Engineering, Universiti Teknologi Mara, Malaysia \\ ${ }^{3}$ Faculty of Engineering, Technology and Built Environment, UCSI University, Malaysia \\ ${ }^{4,5,6}$ Department of Electrical \& Electronics, College of Engineering, Universiti Tenaga Nasional, Malaysia
}

\begin{tabular}{|c|c|}
\hline Article Info & ABSTRACT \\
\hline Article history: & This paper presents the optimal multiple distributed generations (MDGs) \\
\hline Received May 23, 2019 & $\begin{array}{l}\text { installation for improving the voltage profile and minimizing power losses of } \\
\text { distribution system using the integrated monte-carlo evolutionary }\end{array}$ \\
\hline Revised Jun 11, 2019 & programming (EP). EP was used as the optimization technique while monte \\
\hline Accepted Jun 21, 2019 & $\begin{array}{l}\text { carlo simulation is used to find the random number of locations of MDGs. } \\
\text { This involved the testing of the proposed technique on IEEE 69-bus }\end{array}$ \\
\hline Keywords: & $\begin{array}{l}\text { distribution test system. It is found that the proposed approach successfully } \\
\text { solved the MDGs installation problem by reducing the power losses and }\end{array}$ \\
\hline Distributed generation & \\
\hline
\end{tabular}

Evolutionary programming

Losses minimization

Monte carlo simulation

Voltage improvement

Copyright $@ 2019$ Institute of Advanced Engineering and Science. All rights reserved.

\section{Corresponding Author:}

Ismail Musirin,

Faculty of Electrical Engineering,

Universiti Teknologi Mara,

40450 Shah Alam, Selangor, Malaysia.

Email: ismailbm1@gmail.com

\section{INTRODUCTION}

Distribute generation (DG) is a generation of electricity that normally located at the distribution network. This DG acts as auxiliary power sources, which associated to the grid at different places and basically satisfy the load demand that is required [1-3]. Nowadays, DG is vital with a specific end goal to secure and supply the power to the customer, deregulation of power market, decrease environment control and increase the power reliability [4-8]. DG is the idea of decentralizing the power generation by putting small generating units at or close the load center. During most recent couple of decades there have been many changes in the power system industry because improvement in DG advances, economic policy and rebuilding. With fast infiltration of DG into distribution systems, it is basic to evaluate its effects to power system precisely so that these DG units be connected in a way that avoid degradation of power quality, flexibility in control of the utility system and increase reliability. Then again, DG can possibly enhance distribution system performance and it ought to be encouraged [9-14]. In this way, it has turned out to be critical to study changes that DG acquires with a change its area or size of DG.

In the past ten years, many scientists and engineers have proposed methods to solve this DG installation problem. In [15], hybrid particle swarm optimization (HPSO) technique to find the optimal location and sizing for DG in 69-bus radial distribution system was proposed. The radial power flow algorithm (FFRPF) was integrated with particle swarm optimization (PSO) to complete the nonlinear power flow equations. The complex voltages at each bus were describe by power flow equations, and non-linear equality constraints needed to be satisfied during the optimization process is the power flowing in each line 
of the distribution network. The proposed method was tested with fixed power factor of 0.85 and the real output power is being varied. This method is also used fixed power factor to obtain the optimal location of single DG. The results showed the location of the DG placement consistently, which is at bus 61. The proposed technique results both DG size and optimal bus location to minimize power losses. It clear indicates the satisfaction of the technique to solve the optimization matters.

An analytical approach to determine the sizing of distributed generation and optimal placement with different size load models on radiance feeder was proposed in [16]. The load models include increasingly, centrally and uniformly distributions. 13-bus radial feeder system were used by this technique. There are two of different problem are being proposed. The optimal placement and the size of DG is equal to the size of load is the first case. For second case, both of optimal sizing and location are obtained. This algorithm used in this paper is grid search algorithm. It is used to determine the voltage profile and minimize the power losses either it is in within acceptable range or not. The results indicate that the placement of DG and optimal size are not the same for each load profile of distribution. The optimal location does not change with the chosen model and the optimal size of DG is highly influenced by the load models.

Evolutionary Programming Method with Cooling-Banking Constraints was proposed in [17] for solving unit commitment problem (UPC). The main objective of UPC is to determine the status (on/off) of generating units in power system at the minimum operating cost to meet the load demand. The inputs for solving UCP includes the total operating hours, the cost parameters of each thermal system, volume and discharge limits for hydro system, also hydro coefficient of hydro system. This paper compares the total production cost for the methods of Evolutionary Programming (EP), Dynamic Programming (DP), and Evolutionary Programming with Cooling-Banking Constraint. The near optimal solution approached by using Evolutionary Programming with Cooling-Banking Constraint.

In [18], Evolutionary programming (EP) was proposed by considering the power limit to satisfy combined economic emission dispatch (CEED). CEED is used to minimize both of the emission level simultaneously and operating fuel cost to meet the operational constraints and load demand. The results show EP technique has minimized the emission values and fuel cost. The results converge near to global minimum with less search account with high efficiency. This technique is very reliable since the quality of solutions generated by EP offers excellent results, with high accuracy and less computational time.

In [19], evolutionary programming (EP) was proposed by using multi-objective function to allocate the capacitor banks in distribution system. The method is developed to get the optimal sizing and placement of the capacitor banks in IEEE 33-bus system of distribution. The placement of single capacitor, two capacitors and three capacitors are considered. Based on the results, three capacitors installation show the minimum losses of power. Hence, its clarified efficiency of the technique for reduction of power losses in the bus system.

Monte carlo techniques very helpful in recreating networks with many coupled degrees of freedom, for example fluids, disordered materials, interacting particle systems, cellular Potts model and McKeanVlasov processes in physics-related issues. Other cases incorporate calculation of risk in business and in mathematic they modeling phenomena with critical uncertainty in inputs. In application to space and oil exploration issue. Monte carlo-based expectations of failure, cost overruns and schedule overruns are absolutely superior to alternative soft methods or human instinct. Other cases incorporate modeling phenomena with critical uncertainty in inputs such as the calculation of risk in business and, in math, assessment of multidimensional definite integrals with muddled boundary conditions [20-24]

Monte Carlo experiments or strategies depend on repeated random sampling to acquire numerical outcomes and a wide class of computational algorithm. They are frequently utilized as a part of physical and numerical issues and are most valuable when it is troublesome or difficult to utilize different methodologies. Monte Carlo strategies are essentially utilized as a part of three particular issue classes: optimization, numerical integration and getting a draws from probability distribution [25].

This paper focuses on determining the optimal location and size of MDGs using Integrated Monte Carlo-Evolutionary Programming (IMC-EP). This research looks on how the optimal location and sizes of the MDGs can affect the power losses and voltage stability of the distribution system.

\section{METHODOLOGY}

Integrated Monte Carlo-Evolutionary Programming (IMC-EP) is the optimizer for this MDGs installation problem. There are two cases with different objective function in this study. The first case objective function is to minimize power losses and the second case objective function is to improve minimum voltage. Figure 1 shows the flowchart of algorithm for power losses $\left(\mathrm{P}_{\text {losses }}\right)$ as objective function, while Figure 2 shows the the flowchart algorithm of Minimum voltage $\left(\mathrm{V}_{\min }\right)$ as objective function. The details of these algorithms are described in Section 2.1 to Section 2.10. 


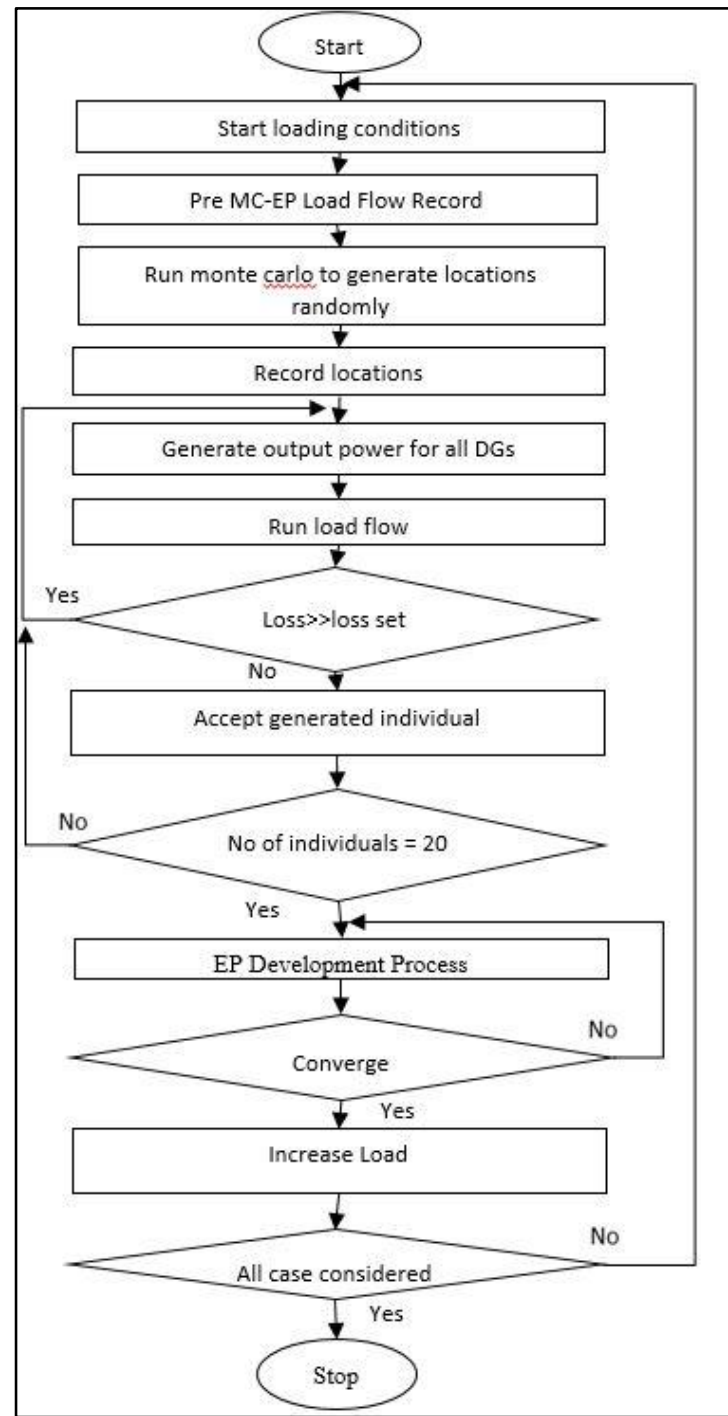

Figure 1. Flow chart of $P_{\text {losses }}$ as objective function

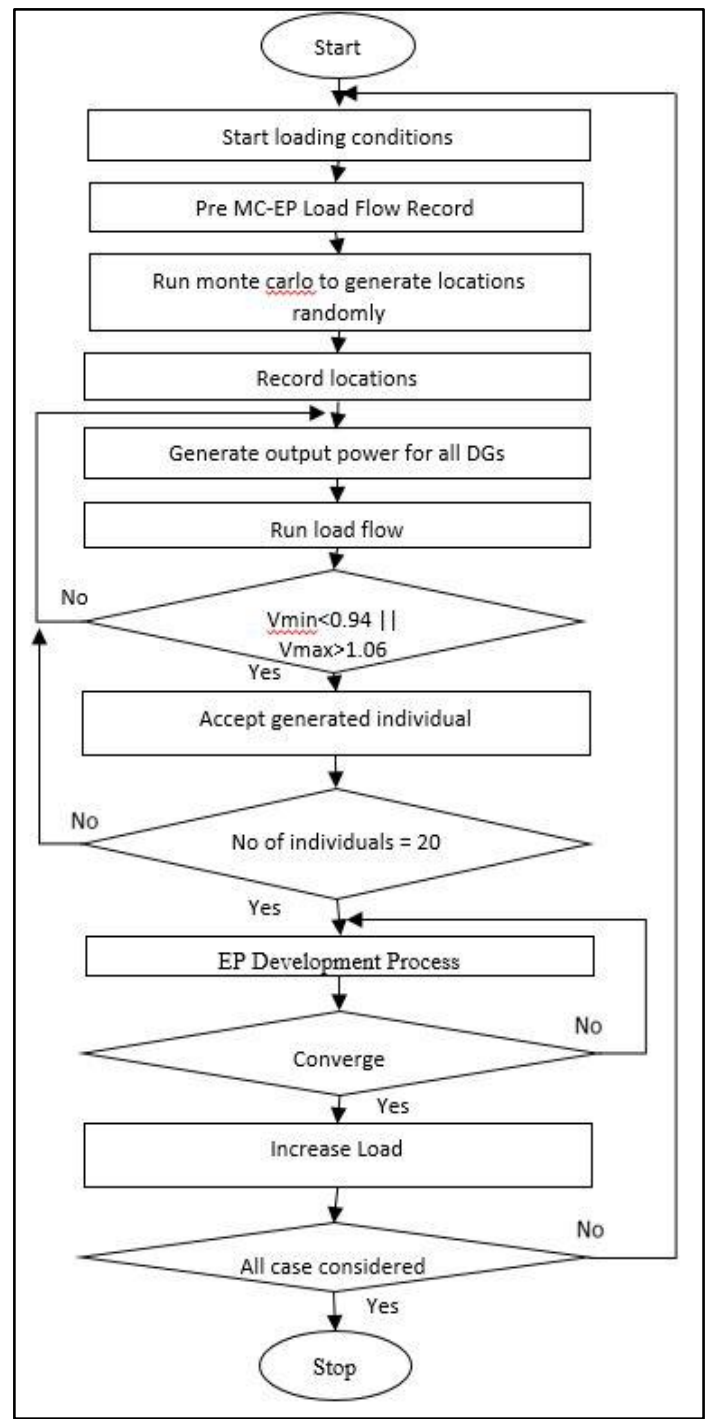

Figure 2. Flow chart of $V_{\min }$ as objective function

\subsection{Pre-optimization}

Condition before optimization process is taken. It represents the initial condition of the 69-Bus system. In this paper, the initial condition of minimum voltage $\left(\mathrm{V}_{\mathrm{m}}\right)$ versus load increment and power losses $\left(\mathrm{P}_{\text {losses }}\right)$ versus load increment are taken for the pre-optimization stage. This is important to find the starting point for the optimal solutions search in the post-optimization. The load increment is subjected from $100 \%$ until $200 \%$ with random bus number.

\subsection{Post-optimization}

In this stage, Integrated Monte Carlo-Evolutionary Programming for solving DG installation problem is implemented. The DG installation problem is solved based on two objective functions: minimizing power losses and Improving voltage profile. It is decided to have three locations of MDGs in the 69-Bus system based on its size. And for the all three locations, it will be installed with real and reactive power sources. The processes of solving it are explained in detail in the following section.

\subsubsection{Initialization}

This part is conducted to generate random location of bus data, represented by $\mathrm{L}_{1}, \mathrm{~L}_{2}$ and $\mathrm{L}_{3}$ using Monte Carlo Simulation to find the best random number of MDGs locations. Subsequently, six variables of real power $(\mathrm{P})$ and reactive power $(\mathrm{Q})$ are generated randomly. These variables $\mathrm{P}_{1}, \mathrm{P}_{2}, \mathrm{P}_{3}$ and $\mathrm{Q}_{1}, \mathrm{Q}_{2}, \mathrm{Q}_{3}$ are 
assigned as real and reactive power generation of MDGs. The random generated number of real power $(\mathrm{P})$ is between $1 \mathrm{MW}$ to $2 \mathrm{MW}$ and random generated number of reactive power $(\mathrm{Q})$ is between $0 \mathrm{Mvar}$ to $1.5 \mathrm{Mvar}$.

\subsubsection{Fitness 1 calculation}

From the initialization variables generated, they are used to calculate the fitness of the optimization. As mentioned earlier, there are two objective functions which are minimizing power losses $\left(\mathrm{P}_{\text {losses }}\right)$ and improving minimum voltage $\left(\mathrm{V}_{\min }\right)$.

\subsubsection{Mutation}

During this process, offspring/children are produced using Gaussian mutation method. The Gaussian mutation equation used to produce the offspring is as shown in (1). All the accepted parents from fitness 1 calculation are mutated to produce the new set of population.

$$
x_{i+m, j}=x_{i, j}+N\left(0, \beta\left(x_{\text {jmax }}-x_{\text {jmin }}\right)\left(\frac{f_{i}}{f_{\text {max }}}\right)\right)
$$

where:

\begin{tabular}{|c|c|c|c|}
\hline$x_{i+m, j}$ & $\begin{array}{l}\text { is mutated parent individual } \\
\text { (offspring) }\end{array}$ & $x_{i j}$ & is parent individual \\
\hline$\beta$ & is mutation scale, $0<\beta<1$ & $x_{\text {jmax }}$ & is maximum random number for every variable \\
\hline$x_{j \min }$ & $\begin{array}{l}\text { is minimum random number for } \\
\text { every variable }\end{array}$ & $f_{i}$ & is fitness for ith random number \\
\hline $\operatorname{nax}$ & is maximum fitness & & \\
\hline
\end{tabular}

\subsubsection{Fitness 2 calculation}

Again, the fitness is calculated using the offspring population of the mutation process. The fitness calculated is based on the objective function of the optimization.

\subsubsection{Combination}

Parents and offspring populations are combined at this stage. Matrix data become double in size, from 20 data to 40 data. This combined population will undergo selection process for the purpose of selecting best individuals.

\subsubsection{Selection}

For the power losses as objective function, the combined individuals are arranged in ascending order. For the minimum voltage objective function, the combined individuals are arranged in descending order.

\subsubsection{Define new generation}

For power losses, 20 individuals that results in producing lowest power losses are selected for the new generation. For power losses, 20 individuals that results in producing highest minimum voltage are selected for the new generation.

\subsubsection{Convergence test}

This process will determine either the maximum and minimum fitness fulfil the desired requirement or not. If fitness does not meet the requirement, the process will be repeated again to the mutation process. The algorithm is considered converged if the difference between the first fitness value with the twentieth fitness value is 0.00001 .

Max. Fitness-Min. Fitness $<0.00001$

\section{RESULTS AND DISCUSSION} objective function.

The optimization results of this MDGs installation problem are divided into two parts based on their

\subsection{Case 1: Power losses as objective function}

Table 1 shows the optimal locations and sizes of MDGs for the power losses as the objective function. The locations of MDGs implemented are different with the load increment based on the results. It is 
important to determine the load demand before installing the MDGs, since the reliability of MDGs differs in the location. This technique can be used in research as the electrical power consumption is expected to increase drastically for the next decade. The optimization converged after 8 iterations.

Table 1. Post-optimization ( $\mathrm{P}_{\text {losses }}$ as objective function)

\begin{tabular}{|c|c|c|c|c|c|c|c|c|c|c|c|c|c|}
\hline \multirow[b]{3}{*}{$\begin{array}{c}\text { Load } \\
\text { increment } \\
(\%)\end{array}$} & \multicolumn{7}{|c|}{ Pre-optimization } & \multicolumn{6}{|c|}{ Post-optimization } \\
\hline & \multirow[b]{2}{*}{$\begin{array}{l}\mathrm{P}_{\text {losses }} \\
(\mathrm{Kw})\end{array}$} & \multirow[b]{2}{*}{$\begin{array}{l}\mathrm{V}_{\min } \\
\text { (p.u) }\end{array}$} & \multirow[b]{2}{*}{$\begin{array}{l}P_{\text {losses }} \\
(\mathrm{Kw})\end{array}$} & \multirow[b]{2}{*}{$\begin{array}{l}\mathrm{V}_{\min } \\
\text { (p.u) }\end{array}$} & \multicolumn{3}{|c|}{ Location } & \multirow[b]{2}{*}{$\begin{array}{c}\text { DG1 } \\
\text { P1 } \\
\text { (MW) }\end{array}$} & \multirow[b]{2}{*}{$\begin{array}{c}\text { DG1 } \\
\text { Q1 } \\
\text { (Mvar) }\end{array}$} & \multicolumn{2}{|c|}{ Size } & \multirow[b]{2}{*}{$\begin{array}{c}\text { DG3 } \\
\text { P3 } \\
\text { (MW) }\end{array}$} & \multirow[b]{2}{*}{$\begin{array}{c}\text { DG3 } \\
\text { Q3 } \\
\text { (Mvar) } \\
\end{array}$} \\
\hline & & & & & L1 & L2 & L3 & & & $\begin{array}{c}\text { DG2 } \\
\text { P2 } \\
(\mathrm{MW})\end{array}$ & $\begin{array}{c}\text { DG2 } \\
\text { Q2 } \\
\text { (Mvar) }\end{array}$ & & \\
\hline $\begin{array}{c}\text { Base Case } \\
(100)\end{array}$ & 0.4088 & 0.8442 & 0.0761 & 0.9599 & 60 & 50 & 56 & 1.7046 & 1.3271 & 1.7399 & 0.7857 & 1.0173 & 0.6932 \\
\hline 125 & 0.4629 & 0.8363 & 0.0787 & 0.9599 & 60 & 50 & 56 & 1.7047 & 1.3272 & 1.7400 & 0.7857 & 1.0174 & 0.6933 \\
\hline 150 & 0.5272 & 0.8281 & 0.0818 & 0.9599 & 60 & 50 & 56 & 1.7048 & 1.3273 & 1.7401 & 0.7858 & 1.0175 & 0.6934 \\
\hline 175 & 0.6026 & 0.8193 & 0.0853 & 0.9599 & 60 & 50 & 56 & 1.7048 & 1.3274 & 1.7401 & 0.7859 & 1.0175 & 0.6934 \\
\hline 200 & 0.6901 & 0.8100 & 0.0893 & 0.9599 & 60 & 50 & 56 & 1.7052 & 1.3277 & 1.7403 & 0.7861 & 1.0180 & 0.6939 \\
\hline
\end{tabular}

Figure 3 shows the load increment versus power losses before and after optimization. It shows that the power losses are increasing drastically with the increasing of load increment. After optimization, power losses are minimized across of all the load increment. It appears that the optimization greatly improved the system's performance. The importance of sufficient reactive power is to provide and maintain the acceptable voltages throughout the system. Reactive power injected by MDGs support the voltage that must be controlled for the system reliability. Insufficient reactive power will cause the minimum voltage to drop. The real power must also be optimized since the flow of reactive power will consume real power thus causing of higher power losses. Hence, it is important to optimize the real power injected to minimize the power losses. Both generated powers contribute towards reliability of system performance with the optimized sizing and location of MDGs.

\subsection{Case 2: Vmin as objective function}

Table 2 shows the optimal locations and sizes of MDGs for Vmin as objective function. It appears that the proposed technique greatly improved the power losses and minimum voltage after optimization. Based on the results, the locations of MDGs are different with the load increment. The power losses lie between the ranges of $0.1 \mathrm{MW}$ to $0.9 \mathrm{~kW}$, which is slightly higher than the power losses in case 1 . All of the minimum voltage approach 0.95 p.u. Minimum voltage values indicate voltage stability which leads towards stability system even the load is increasing. The optimization of the sizing and location converged after 5 iterations.

Figure 4 shows the load increment versus minimum voltage before and after optimizations. It shows the pattern of decreasing in minimum voltage as the load increases before optimization. After being optimized, minimum voltage is improved significantly and constant across all of the load increment. After installing MDGs, the reactive power injected will support the minimum voltage in the system. Decreasing of reactive power causes the voltage to drop. By optimizing the reactive power, the voltage required to deliver the real power to the end consumer will be improved significantly.

Table 2. Post-optimization ( $\mathrm{V}_{\min }$ as objective function)

\begin{tabular}{|c|c|c|c|c|c|c|c|c|c|c|c|c|c|}
\hline \multirow[b]{3}{*}{$\begin{array}{c}\text { Load } \\
\text { increment } \\
(\%)\end{array}$} & \multirow{2}{*}{\multicolumn{4}{|c|}{ Pre-optimization }} & \multirow{2}{*}{\multicolumn{3}{|c|}{ Location }} & \multirow{2}{*}{\multicolumn{6}{|c|}{$\begin{array}{c}\text { Post-optimization } \\
\text { Size }\end{array}$}} \\
\hline & & & & & & & & & & & & & \\
\hline & $\begin{array}{l}\mathrm{P}_{\text {losses }} \\
(\mathrm{Kw})\end{array}$ & $\begin{array}{l}\mathrm{V}_{\min } \\
\text { (p.u) }\end{array}$ & $\begin{array}{l}P_{\text {losses }} \\
(\mathrm{Kw})\end{array}$ & $\begin{array}{l}\mathrm{V}_{\text {min }} \\
\text { (p.u) }\end{array}$ & L1 & L2 & L3 & $\begin{array}{c}\text { DG1 } \\
\text { P1 } \\
\text { (MW) }\end{array}$ & $\begin{array}{c}\text { DG1 } \\
\text { Q1 } \\
\text { (Mvar) }\end{array}$ & $\begin{array}{c}\text { DG2 } \\
\text { P2 } \\
(\mathrm{MW})\end{array}$ & $\begin{array}{c}\text { DG2 } \\
\text { Q2 } \\
\text { (Mvar) }\end{array}$ & $\begin{array}{c}\text { DG3 } \\
\text { P3 } \\
\text { (MW) }\end{array}$ & $\begin{array}{c}\text { DG3 } \\
\text { Q3 } \\
\text { (Mvar) } \\
\end{array}$ \\
\hline $\begin{array}{c}\text { Base Case } \\
(100)\end{array}$ & 0.4088 & 0.8442 & 0.1767 & 0.9479 & 47 & 48 & 65 & 1.3835 & 0.0519 & 1.5194 & 0.0802 & 1.8310 & 0.1767 \\
\hline 125 & 0.4629 & 0.8363 & 0.1863 & 0.9475 & 47 & 48 & 65 & 1.3835 & 0.0519 & 1.5194 & 0.0802 & 1.8310 & 0.1863 \\
\hline 150 & 0.5272 & 0.8281 & 0.1971 & 0.9471 & 47 & 48 & 65 & 1.3835 & 0.0519 & 1.5194 & 0.0802 & 1.8310 & 0.1971 \\
\hline 175 & 0.6026 & 0.8193 & 0.2092 & 0.9467 & 47 & 48 & 65 & 1.3835 & 0.0519 & 1.5194 & 0.0802 & 1.8310 & 0.2092 \\
\hline 200 & 0.6901 & 0.8100 & 0.9565 & 0.9451 & 22 & 36 & 57 & 1.8337 & 1.2025 & 1.7262 & 0.9474 & 1.3290 & 0.9565 \\
\hline
\end{tabular}




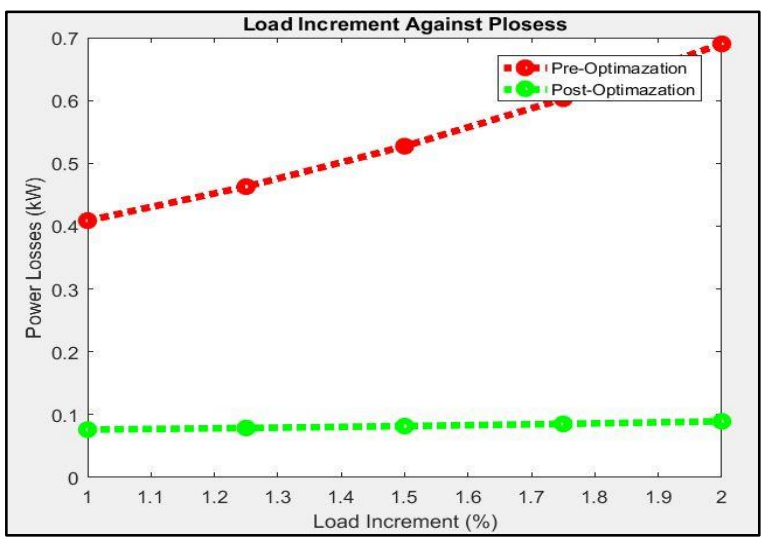

Figure 3. Load increment against power losses

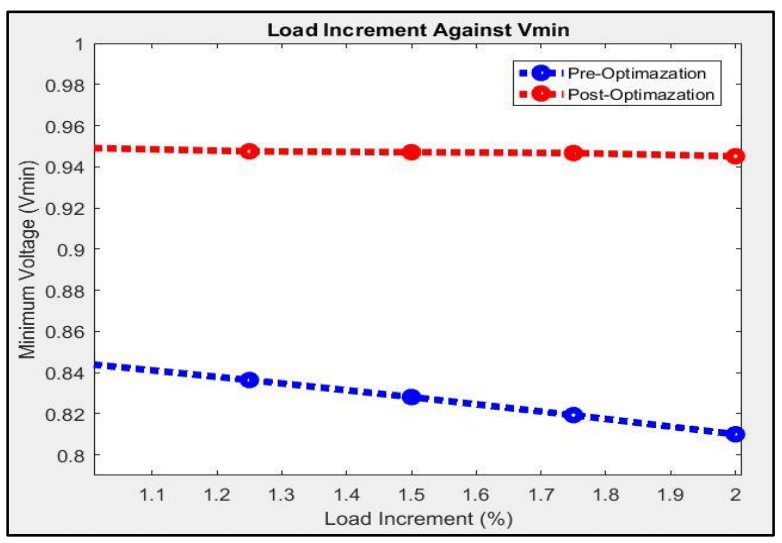

Figure 4. Load increment against minimum voltage

\subsection{Comparison of objective functions}

Table 3 shows the comparison of power losses between the two objective functions. Based on the result, $\mathrm{P}_{\text {losses }}$ objective function performs better for the load increment until $200 \%$ as it showing lower losses compared to $\mathrm{V}_{\text {min }}$ objective function. Hence, it is concluded that $\mathrm{P}_{\text {losses }}$ as objective function is more favorable to be used to determine minimum power losses in the IMC-EP optimization technique.

Table 4 shows the comparison of minimum voltage for the objective functions of $\mathrm{P}_{\text {losses }}$ and $\mathrm{V}_{\text {min }}$. Based on the result, $\mathrm{P}_{\text {losses }}$ as objective function performs better for the load increment until $200 \%$ as it's values approaching to $1 \mathrm{pu}$. While $\mathrm{V}_{\min }$ objective function for load increment does not meet the expected value, where the expected $\mathrm{V}_{\min }$ in this optimization must be greater than 0.95 p.u.

Table 3. Comparison between objective functions to determine power losses

\begin{tabular}{ccc}
\hline $\begin{array}{c}\text { Load increment } \\
(\%)\end{array}$ & $\begin{array}{c}\mathrm{P}_{\text {losses }} / \mathrm{KW} \\
\left(\mathrm{P}_{\text {losses }} \text { as obj. function }\right)\end{array}$ & $\begin{array}{c}\mathrm{P}_{\text {losses }} / \mathrm{KW} \\
\left(\mathrm{V}_{\text {min }} \text { as obj. function }\right)\end{array}$ \\
\hline 100 & 0.0761 & 0.1767 \\
125 & 0.0787 & 0.1863 \\
150 & 0.0818 & 0.1971 \\
175 & 0.0853 & 0.2092 \\
200 & 0.0893 & 0.9565 \\
\hline
\end{tabular}

Table 4. Comparison between objective functions to determine minimum voltage

\begin{tabular}{ccc}
\hline $\begin{array}{c}\text { Load increment } \\
(\%)\end{array}$ & $\begin{array}{c}\mathrm{V}_{\min } / \mathrm{p} . \mathrm{u} \\
\left(\mathrm{P}_{\text {losses }} \text { as obj. }\right. \\
\text { function })\end{array}$ & $\begin{array}{c}\mathrm{V}_{\text {min }} / \mathrm{p} . \mathrm{u} \\
\left(\mathrm{V}_{\min } \text { as obj. }\right. \\
\text { function })\end{array}$ \\
\hline 100 & 0.9599 & 0.9479 \\
125 & 0.9599 & 0.9475 \\
150 & 0.9599 & 0.9471 \\
175 & 0.9599 & 0.9467 \\
200 & 0.9599 & 0.9451 \\
\hline
\end{tabular}

\section{CONCLUSION}

The performances before and after the implementation of MDGs on 69-Bus system have been presented in this paper. Integrated Monte Carlo-Evolutionary Programming (IMC-EP) optimization technique has shown its capability to find the optimal location and sizes of MDGs with the objective to improve the voltage profile and reduce the real power losses in the distribution system. All of the objectives in this study have been significantly achieved.

However, there is still room for improvement. For instance, instead of using Gaussian mutation to produce offspring, other optimization technique such as particle swarm optimization (PSO) and kinetic gas molecule optimization (KGMO) can be integrated into EP to replace the Gaussian mutation to get fitter individuals of offspring. Furthermore, other types of DG also can be installed in the system to see more comprehensive MDGs installation solution.

\section{ACKNOWLEDGEMENTS}

The authors would like to acknowledge The Institute of Research Management and Innovation (IRMI) UiTM, Shah Alam, Selangor, Malaysia and Ministry of Higher Education (MOHE) for the support of this research. This research is supported by Ministry of Higher Education (MOHE) under the Fundamental Research Grant Scheme (FRGS) with project code: 600-RMI/FRGS 5/3 (0102/2016). 


\section{REFERENCES}

[1] A. Dube, M. Rizwan and M. Jamil, "Passive islanding detection technique for multi-DG power system," 2015 Annual IEEE India Conference (INDICON), New Delhi, 2015, pp. 1-6.

[2] M. Bakhshi, R. Noroozian and G. B. Gharehpetian, "Passive anti-islanding scheme based on reactive power in the smart grids," Iranian Conference on Smart Grids, Tehran, 2012, pp. 1-7.

[3] N. Rugthaicharoencheep, T. Lantharthong and S. Auchariyamet, "Optimal operation for active management of distribution system with distributed generation," 2011 International Conference on Clean Electrical Power (ICCEP), Ischia, 2011, pp. 715-719.

[4] A. D. T. L. M. A. Kashem, M. Negnevitsky, and G. Ledwich, "Distributed Generation for Minimization of Power Losses in Distribution Systems," IEEE Power Engineering Society General Meeting, p. pp. 8, 2006.

[5] D. S. M. Z. Dr. Hani M. Baniodeh, Dr. Abdaslam Eajal, "The Pest Location And Size of Distributed Generation (DG) in A Radial Distribution Systems," International Journal of Advanced Research in Electrical, Electronics and Instrumentation Engineering, vol. 2, October 2013.

[6] M. H. Mansor, I. Musirin, M. M. Othman, S. A. Shaaya, and S. A. S. Mustaffa, "Application of Immune LogNormal Evolutionary Programming in Distributed Generation Installation," Indones. J. Electr. Eng. Comput. Sci., vol. 6, no. 3, pp. 730-736, 2017.

[7] N. C. N. a. D. C. C. A. Rajan, "A Novel Approach for Solving Unit Commitment Problem using Evolutionary Programming Method with Cooling-Banking Constraints," Indian Journal of Applied Research, vol. 3, pp. 45, January 2013.

[8] K. S. M.E., "Combined Economic Emission Dispatch using Evolutinary Programming Technique," International Journal of Computer Applications ECOT (2), pp. 62-66, 2010.

[9] N. Ghadimi, "Allocation of Capacitor Banks in Distribution Systems using Multi-Objective Function," Academic Journals, vol. 8, no. 27, pp. 1282-1288, July 2013.

[10] L. R. Martino, Jesse, "On the flexibility of the design of multiple try Metropolis schemes," Computational Statistics, pp. 2797-2823, 2013.

[11] D. P. B. Kroese, T. Taimre, T. Botev, Z. I., "Why the Monte Carlo method is so important today," WIREs Comput Stat., pp. 386-392, 2014.

[12] S. R. Abdul Rahim, T. K. A. Rahman, P. D. I. Musirin, M. H. Hussain, M. H. Sulaiman, O. Aliman, and Z. mat isa, "Implementation of DG for loss minimization and voltage profile in distribution system," in PEOCO 2010-4th International Power Engineering and Optimization Conference, Program and Abstracts, pp. 490-494, 2010.

[13] M. Esmaili, E. C. Firozjaee, and H. A. Shayanfar, "Optimal placement of distributed generations considering voltage stability and power losses with observing voltage-related constraints," Appl. Energy, vol. 113, pp. 1252-1260, 2014.

[14] M. M. Othman, W. El-Khattam, Y. G. Hegazy, and A. Y. Abdelaziz, "Optimal placement and sizing of voltage controlled distributed generators in unbalanced distribution networks using supervised firefly algorithm," Int. J. Electr. Power Energy Syst., vol. 82, pp. 105-113, 2016.

[15] W. J. Liu, M. Chi, Z. W. Liu, Z. H. Guan, J. Chen, and J. W. Xiao, "Distributed optimal active power dispatch with energy storage units and power flow limits in smart grids," Int. J. Electr. Power Energy Syst., vol. 105, no. May 2018, pp. 420-428, 2019.

[16] X. K. Liu, Y. W. Wang, H. Yan, X. Wang, and X. Hu, "Hybrid Consensus-based Algorithm for Distributed Economic Dispatch Problem," IFAC-PapersOnLine, vol. 50, no. 1, pp. 177-182, 2017.

[17] L. Mokgonyana, J. Zhang, H. Li, and Y. Hu, "Optimal location and capacity planning for distributed generation with independent power production and self-generation," Appl. Energy, vol. 188, pp. 140-150, 2017.

[18] E. S. Ali, S. M. Abd Elazim, and A. Y. Abdelaziz, "Ant Lion Optimization Algorithm for renewable Distributed Generations," Energy, vol. 116, pp. 445-458, 2016.

[19] R. J. Flores, B. P. Shaffer, and J. Brouwer, "Dynamic distributed generation dispatch strategy for lowering the cost of building energy," Appl. Energy, vol. 123, pp. 196-208, 2014.

[20] E. S. Oda, A. A. Abdelsalam, M. N. Abdel-Wahab, M. M. El-Saadawi, "Distributed generations planning using flower pollination algorithm for enhancing distribution system voltage stability," Ain Shams Eng. J., vol. 8, no. 4, pp. 593-603, December 2017

[21] S. Devi and M. Geethanjali, "Optimal location and sizing determination of Distributed Generation and DSTATCOM using Particle Swarm Optimization algorithm," Int. J. Electr. Power Energy Syst., vol. 62, pp. 562-570, 2014.

[22] L. I. Dulău, M. Abrudean, and D. Bică, "Optimal Location of a Distributed Generator for Power Losses Improvement," Procedia Technol., vol. 22, pp. 734-739, 2016.

[23] C. Ma, P. Kaufmann, J. C. Töbermann, and M. Braun, "Optimal generation dispatch of distributed generators considering fair contribution to grid voltage control," Renew. Energy, vol. 87, pp. 946-953, 2016.

[24] M. Pesaran H.A, P. D. Huy, and V. K. Ramachandaramurthy, "A review of the optimal allocation of distributed generation: Objectives, constraints, methods, and algorithms," Renew. Sustain. Energy Rev., vol. 75, pp. 293-312, 2017.

[25] B. Singh, V. Mukherjee, and P. Tiwari, "GA-based multi-objective optimization for distributed generations planning with DLMs in distribution power systems," J. Electr. Syst. Inf. Technol., vol. 4, no. 1, pp. 62-94, May 2017. 